\title{
Response: Where Might We Find Ecologically Intact Communities?
}

\author{
Hedley S. Grantham ${ }^{1 *}$, Tom Evans ${ }^{1}$, Susan Lieberman ${ }^{1}$, John G. Robinson ${ }^{1}$, \\ Paul R. Elsen ${ }^{1}$, Simon Ferrier ${ }^{2}$, Stephen G. Kearney ${ }^{3}$, Golo Maurer ${ }^{4}$, Gautam Surya ${ }^{1}$, \\ Rebecca Spindler ${ }^{5}$, Basha Stasak ${ }^{6}$, James Trezise ${ }^{7}$ and James E. M. Watson ${ }^{3}$ \\ ${ }^{1}$ Wildlife Conservation Society, Global Conservation Program, Bronx, NY, United States, ${ }^{2}$ Commonwealth Scientific and \\ Industrial Research Organisation (CSIRO) Land and Water, Canberra, ACT, Australia, ${ }^{3}$ Centre for Biodiversity and \\ Conservation Science, School of Earth and Environmental Sciences, University of Queensland, Brisbane, QLD, Australia, \\ ${ }^{4}$ BirdLife Australia, Melbourne, Australia and College of Marine \& Environmental Sciences and Australian Tropical Herbarium, \\ James Cook University, Nguma-bada Campus, Smithfield, QLD, Australia, ${ }^{5}$ Bush Heritage Australia, Melbourne, VIC, \\ Australia, ${ }^{6}$ Australian Conservation Foundation, Carlton, VIC, Australia, ${ }^{7}$ Invasive Species Council, Katoomba, NSW, Australia
}

Keywords: Key Biodiversity Areas (KBAs), biodiversity, intact communities, ecological integrity assessment, Convention on Biodiversity (CBD)

\section{OPEN ACCESS}

Edited by:

Barry Alan Gardiner,

Institut Européen De La Forêt Cultivée (IEFC), France

Reviewed by: Mark Andrew Adams,

Swinburne University of Technology, Australia

*Correspondence: Hedley S. Grantham hgrantham@wcs.org

Specialty section: This article was submitted to Forest Disturbance, a section of the journal Frontiers in Forests and Global Change

Received: 25 June 2021 Accepted: 04 February 2022 Published: 04 March 2022

Citation:

Grantham HS, Evans T, Lieberman S, Robinson JG, Elsen PR, Ferrier S, Kearney SG, Maurer G, Surya G,

Spindler R, Stasak B, Trezise $J$ and Watson JEM (2022) Response: Where Might We Find Ecologically Intact

Communities?

Front. For. Glob. Change 5:730546. doi: 10.3389/ffgc.2022.730546

\section{A Commentary on}

Where Might We Find Ecologically Intact Communities?

by Plumptre, A. J., Baisero, D., Belote, R. T., Vázquez-Domínguez, E., Faurby, S., Jędrzejewski, W., et al. (2021). Front. For. Glob. Change 4:626635. doi: 10.3389/ffgc.2021.626635

\section{INTRODUCTION}

In an attempt to identify areas of the world that represent outstanding examples of ecological integrity, Plumptre et al. (2021) concluded that just $2.8 \%$ of Earth's terrestrial area could be considered to qualify. This analysis contrasts with other global assessments that show the extent of areas important for ecological integrity to be at least an order of magnitude higher (Newbold et al., 2016; Watson et al., 2016a; Beyer et al., 2020; Grantham et al., 2020; Hansen et al., 2020; Mokany et al., 2020; Riggio et al., 2020; Williams et al., 2020; De Palma et al., 2021). Plumptre et al. (2021) further argue their methodology and findings can inform Key Biodiversity Area (KBA) delineation.

We believe the methodology used by Plumptre et al. is highly problematic when it comes to scoping sites in relation to ecological integrity. We provide reasons why their methodology is inappropriate for the scoping of KBA site identification (IUCN, 2016). We urge readers of Plumptre et al. (2021) to consider carefully their interpretations of data and underlying ecological theory, the problems inherent in the methodology employed in the analysis, and how the results can be misrepresented in important and ongoing global policy discussions.

\section{Definition of Ecological Integrity}

Intact areas are synonymous with locations of high ecosystem integrity. They are associated with ecosystem characteristics of relatively undisturbed ecosystem functioning, structure, and composition (Nicholson et al., 2021). Plumptre et al. (2021) combine three types of measures of "intactness" to measure ecological integrity. The first is use of Human Footprint Index to identify areas of low human impact. The second is to require "faunal intactness" meaning that no faunal species have been lost historically, while the third is to require "functional intactness," meaning that none of the faunal species of interest have densities less than a somewhat arbitrary threshold. 
This narrow species-focused approach to defining ecological integrity does not align with other definitions of ecological integrity that have been used for over three decades (Noss, 1990; Parrish et al., 2003; Keith et al., 2013). Such established definitions consistently focus on a balanced assessment of complementary ecosystem attributes of function, structure, and composition (relative to a reference state and measured on a spectrum, Nicholson et al., 2021). These established definitions have been used in the Convention on Biological Diversity (CBD) (OEWG, 2020) and in formulating appropriate targets and indicators (Hansen et al., 2021; Nicholson et al., 2021). Plumptre et al. use the combination of the three species-related thresholds to define a binary framework, within which a site is either "ecologically intact" or not. This is clearly counter to traditional definitions of ecological integrity that have typically been measured and understood along a spectrum (Wurtzebach and Schultz, 2016).

In essence, the Plumptre et al. definition requires that sites cannot have "outstanding integrity" if just one faunal species has been lost, or if there is evidence of "reduced abundance." We question the utility of such a definition. It is both theoretically and practically impossible to quantify species abundance for so many species (Whittaker et al., 2005). Whilst highlighting impacts of human activity on single species can be useful (e.g., Di Marco et al., 2018; O’Bryan et al., 2020), disregarding all other aspects of ecological integrity which may remain high in such places (i.e., those aspects associated with function, structure, and other elements of species composition; see also Hansen et al., 2021; Nicholson et al., 2021), is a very narrow view. Plumptre's et al.'s binary measurement also implies that areas which are not "perfect," are not intact (in the sense of overall species composition). Applying this approach to the marine realm would likely lead to a conclusion that none of the world's oceans (or even parts thereof) have outstanding ecological integrity (e.g., absence or reduced abundance of some cetacean species due to historical whaling). Interpreting integrity in this way is unhelpful to identifying priority areas for either research or conservation.

The threshold approach used by Plumptre et al. does not consider the critical issue of constant species turnover. Over longer time scales, locally extirpated species can be replaced through natural processes and there is often redundancy in ecosystem function (Gonzalez and Loreau, 2009; Walther, 2010). It also does not consider climate change, a phenomenon that is already leading to shifting and changing communities, with its often unknown consequences for ecosystem functions (Gonzalez and Loreau, 2009; Hobbs et al., 2009; Walther, 2010; Pacifici et al., 2015). Using the Plumptre et al. (2021) definition, no areas would likely qualify as intact owing to unknown but highly likely climate effects on species abundances.

\section{Mapping Ecological Integrity}

We can see at least five problems with the Plumptre et al. approach. Each, by themselves, render the results unreliable as a depiction of the current state of terrestrial ecological integrity.

First, Plumptre et al. used an arbitrary threshold (value of $\leq 4)$ derived from the Human Footprint (HFP) Index (Venter et al., 2016) to define areas of high ecological integrity. We know of no compelling scientific evidence that the HFPI is a sound basis for quantifying faunal abundance or functional intactness (see discussions in Di Marco et al., 2018; Watson et al., 2018; Mokany et al., 2020; O’Bryan et al., 2020). A threshold of $\leq 4$ for a species does not mean that habitat scoring $>4$ is not important. Indeed, for mammals there is clear evidence that a wide range of HFP scores are associated with discrete mammal habitats (Di Marco et al., 2018). An arbitrary choice of a threshold is, in fact, central to all Plumptre et al.'s results and conclusions. Threshold choice immediately excludes $>50 \%$ of Earth's terrestrial surface (see analysis in Watson et al., 2016b). Put another way, many areas considered by Plumptre et al. are simply discounted a priori, for no reason other than their HFP score is $>4$.

Second, Plumptre et al.'s analysis relies on identifying "extinct species," based on both global extinction and local extirpation. Plumptre et al. use a reference date of 1,500 AD. Such an arbitrary date has no scientific basis, as far as we are aware. Third, Plumptre et al. use historical species range data, that are known to be questionable (Rondinini et al., 2006; Jetz et al., 2008). The "range maps" relied upon by Plumptre et al. overestimate where species may have become extinct or extirpated. Use of these maps also assumes precision and accuracy of historical data for each species. Such data are typically inaccurate for even the most well-studied species and over timeframes of the last 50 years, let alone the last 500 years (Ramesh et al., 2017). Fourth, to estimate "functional intactness," Plumptre et al. use a set of indicators, based on reductions in density or habitat suitability for just 11 extant faunal species (some divided into subspecies), mostly different species of apes (superfamily: Hominoidea) and bears (family Ursidae). While we recognize that some of these might be keystone species (e.g., the African forest elephant Loxodonta cyclotis) (Blake et al., 2009), it is highly unlikely that these species are representative of the thousands of species in many ecosystems, and millions of species worldwide (Mora et al., 2011). There is no evidence to suggest these are representative species in most ecosystems. Fifth, four of the five suitability models used by Plumptre et al. (see Luna-Aranguré et al., 2020) to create a functional intactness metric were based solely on species' environmental niches. Such analysis lacks sensitivity to human impacts, a major driver of species response.

\section{Policy Commentary}

In addition to the methodological issues we outline above, we believe the Plumptre et al. study to be unsuited as a basis for policy (Wurtzebach and Schultz, 2016). Parties to the Convention on Biological Diversity (CBD) are currently negotiating the post-2020 Global Biodiversity Framework (GBF). ${ }^{1}$ The current draft of the $\mathrm{GBF}^{2}$ represents a growing consensus among the 196 governments that are Parties to the CBD (all but two of the world's national governments). The draft GBF states, "By 2030 [50\%], of land and sea areas globally are under spatial planning addressing land/sea use change, retaining most of the existing intact and wilderness areas, and allow to restore [X\%] of degraded freshwater, marine and terrestrial natural ecosystems

\footnotetext{
${ }^{1}$ https://www.cbd.int/conferences/post2020

${ }^{2}$ https://www.cbd.int/doc/c/3064/749a/0f65ac7f9def86707f4eaefa/post2020-prep02-01-en.pd
} 
and connectivity among them." While it might not have been the authors intention, their study could undermine existing efforts to protect and retain ecosystems that, using more common and robust measures, are regarded as being intact or of high integrity. Plumptre et al. argue that there are areas where rewilding is possible and that reintroducing a handful of vertebrate species into degraded ecosystems somehow will increase their intactness to allow it to then become a high integrity site. This is a peculiar interpretation that owes much to narrowly species-focused data.

We believe retaining all Earth's highly intact ecosystems should remain a focus of policy discussions. This is a more cost-effective approach than hoping to restore an ecosystem after it has been destroyed or degraded. Finally, and beyond the issues raised above, Plumptre et al. suggest that there are very few global sites that would qualify as intact under the IUCN

\section{REFERENCES}

Beyer, H. L., Venter, O., Grantham, H. S., and Watson, J. E. (2020). Substantial losses in ecoregion intactness highlight urgency of globally coordinated action. Conserv. Lett. 13, e12692. doi: 10.1111/conl.12692

Blake, S., Deem, S. L., Mossimbo, E., Maisels, F., and Walsh, P. (2009). Forest elephants: tree planters of the Congo. Biotropica 41, 459-468. doi: 10.1111/j.1744-7429.2009.00512.x

De Palma, A., Hoskins, A., Gonzalez, R. E., Börger, L., Newbold, T., SanchezOrtiz, K., et al. (2021). Annual changes in the Biodiversity Intactness Index in tropical and subtropical forest biomes, 2001-2012. Sci. Rep. 11, 1-13. doi: 10.1038/s41598-021-98811-1

Di Marco, M., Venter, O., Possingham, H. P., and Watson, J. E. M. (2018). Changes in human footprint drive changes in species extinction risk. Nat. Commun. 9, 1-9. doi: 10.1038/s41467-018-07049-5

Gonzalez, A., and Loreau, M. (2009). The causes and consequences of compensatory dynamics in ecological communities. Annu. Rev. Ecol. Evol. Syst. 40, 393-414. doi: 10.1146/annurev.ecolsys.39.110707.173349

Grantham, H., Duncan, A., Evans, T., Jones, K., Beyer, H., Schuster, R., et al. (2020). Anthropogenic modification of forests means only $40 \%$ of remaining forests have high ecosystem integrity. Nat. Commun. 11, 1-10. doi: 10.1101/2020.03.05.978858

Hansen, A. J., Burns, P., Ervin, J., Goetz, S. J., Hansen, M., Venter, O., et al. (2020). A policy-driven framework for conserving the best of Earth's remaining moist tropical forests. Nat. Ecol. Evol. 4, 1377-1384. doi: 10.1038/s41559-020-1274-7

Hansen, A. J., Noble, B. P., Veneros, J., East, A., Goetz, S. J., Supples, C., et al. (2021). Towards monitoring ecosystem integrity within the post-2020 global biodiversity framework. Conserv. Lett. 4, e12822. doi: 10.1111/conl.12822

Hobbs, R. J., Higgs, E., and Harris, J. A. (2009). Novel ecosystems: implications for conservation and restoration. Trends Ecol. Evol. 24, 599-605. doi: 10.1016/j.tree.2009.05.012

IUCN (2016). A Global Standard for the Identification of Key Biodiversity Areas. Version 1, 20162048. Gland.

Jetz, W., Sekercioglu, C. H., and Watson, J. E. M. (2008). Ecological correlates and conservation implications of overestimating species geographic ranges. Conserv. Biol. 22, 110119. doi: 10.1111/j.1523-1739.2007.00847.x

Keith, D. A., Rodríguez, J. P., Rodríguez-Clark, K. M., Nicholson, E., Aapala, K., Alonso, A., et al. (2013). Scientific foundations for an IUCN red list of ecosystems. PLoS ONE 8, e62111. doi: 10.1371/journal.pone.0062111

Luna-Aranguré, C., Soberón, J., and Vázquez-Domínguez, E. (2020). A tale of four bears: environmental signal on the phylogeographical patterns within the extant Ursus species. J. Biogeogr. 47, 472-486. doi: 10.1111/jbi.13752

Mokany, K., Ferrier, S., Harwood, T. D., Ware, C., Di Marco, M., Grantham, H. S., et al. (2020). Reconciling global priorities for conserving biodiversity habitat. Proc. Natl. Acad. Sci. 117, 9906-9911. doi: 10.1073/pnas.19183 73117
Standard's Criterion C. We suggest more judicious application of criteria of structure, function, and composition would result in many more sites globally being recognized as having outstanding ecological integrity.

In summary, we question the approach and methods used by Plumptre et al. We are concerned to ensure that assessments of ecological intactness and integrity are as robust as possible, and that policy discussions remain based on the best science possible.

\section{AUTHOR CONTRIBUTIONS}

HG and JW wrote the first draft. All other coauthors contributed to the text. All authors contributed to the article and approved the submitted version.

Mora, C., Tittensor, D. P., Adl, S., Simpson, A. G., and Worm, B. (2011). How many species are there on Earth and in the ocean? PLoS Biol. 9, e1001127. doi: 10.1371/journal.pbio.1001127

Newbold, T., Hudson, L. N., Arnell, A. P., Contu, S., De Palma, A., Ferrier, S., et al. (2016). Has land use pushed terrestrial biodiversity beyond the planetary boundary? A global assessment. Science 353, 288-291. doi: 10.1126/science.aaf2201

Nicholson, N., Watermeyer, K. E., Rowland, J., Sato, C. F., Stevenson, S., Andrade, A., et al. (2021). Scientific foundations for an ecosystem goal, milestones and indicators for the post-2020 global biodiversity framework. Nat. Ecol. Evol. 5, 1338-1349. doi: 10.1038/s41559-021-01538-5

Noss, R. F. (1990). Indicators for monitoring biodiversity: a hierarchical approach. Conserv. Biol. 4, 355-364. doi: 10.1111/j.1523-1739.1990.tb00309.x

O’Bryan, C. J., Allan, J. R., Holden, M., Sanderson, C., Venter, O., Di Marco, M., et al. (2020). Intense human pressure is widespread across terrestrial vertebrate ranges. Global Ecol. Conserv. 21, e00882. doi: 10.1016/j.gecco.2019.e00882

OEWG (2020). Update of the Zero Draft of the Post 2020 Global Biodiversity Framework. CBD/POST2020/PREP/2/1. Open-Ended Working Group on the Post-2020 Global Biodiversity Framework. Available online at: https://www. cbd.int/conferences/post2020

Pacifici, M., Foden, W. B., Visconti, P., Watson, J. E., Butchart, S. H., Kovacs, K. M., et al. (2015). Assessing species vulnerability to climate change. Nat. Clim. Change 5, 215-224. doi: 10.1038/nclimate2448

Parrish, J. D., Braun, D. P., and Unnasch, R. S. (2003). Are we conserving what we say we are? Measuring ecological integrity within protected areas. BioScience 53, 851-860. doi: 10.1641/0006-3568(2003)0530851:AWCWWS2.0.CO;2

Plumptre, A. J., Baisero, D., Belote, R. T., Vázquez-Domínguez, E., Faurby, S., J?drzejewski, W., et al. (2021). Where might we find ecologically intact communities? Front. Forests Global Change 4, 26. doi: 10.3389/ffgc.2021.626635

Ramesh, V., Gopalakrishna, T., Barve, S., and Melnick, D. J. (2017). IUCN greatly underestimates threat levels of endemic birds in the Western Ghats. Biol. Conserv. 210, 205-221. doi: 10.1016/j.biocon.2017.03.019

Riggio, J., Baillie, J. E., Brumby, S., Ellis, E., Kennedy, C. M., Oakleaf, J. R., et al. (2020). Global human influence maps reveal clear opportunities in conserving Earth's remaining intact terrestrial ecosystems. Global Change Biol. 26, 4344-4356. doi: 10.1111/gcb.15109

Rondinini, C., Wilson, K. A., Boitani, L., Grantham, H., and Possingham, H. P. (2006). Tradeoffs of different types of species occurrence data for use in systematic conservation planning. Ecol. Lett. 9, 1136-1145. doi: 10.1111/j.1461-0248.2006.00970.x

Venter, O., Sanderson, E. W., Magrach, A., Allan, J. R., Beher, J., Jones, K. R., et al. (2016). Global terrestrial human footprint maps for 1993 and 2009. Sci. Data 3, 1-10. doi: 10.1038/sdata.2016.67

Walther, G.-R. (2010). Community and ecosystem responses to recent climate change. Philos. Trans. R. Soc. B Biol. Sci. 365, 2019-2024. doi: $10.1098 /$ rstb.2010.0021 
Watson, J. E., Evans, T., Venter, O., Williams, B., Tulloch, A., Stewart, C., et al. (2018). The exceptional value of intact forest ecosystems. Nat. Ecol. Evol. 2, 599-610. doi: 10.1038/s41559-018-0490-x

Watson, J. E. M., Jones, K. R., Fuller, R. A., Marco, M. D., Segan, D. B., Butchart, S. H. M., et al. (2016b). Persistent disparities between recent rates of habitat conversion and protection and implications for future global conservation targets. Conserv. Lett. 9, 413-421. doi: 10.1111/conl.12295

Watson, J. E. M., Shanahan, D. F., Di Marco, M., Allan, J., Laurance, W. F., Sanderson, E. W., et al. (2016a). Catastrophic declines in wilderness areas undermine global environment targets. Curr. Biol. 26, 2929-2934. doi: 10.1016/j.cub.2016.08.049

Whittaker, R. J., Araújo, M. B., Jepson, P., Ladle, R. J., Watson, J. E. M., and Willis, K. J. (2005). Conservation biogeography: assessment and prospect. Diversity Distribut. 11, 3-23. doi: 10.1111/j.1366-9516.2005.00143.x

Williams, B. A., Venter, O., Allan, J. R., Atkinson, S. C., Rehbein, J. A., Ward, M., et al. (2020). Change in terrestrial human footprint drives continued loss of intact ecosystems. One Earth 3, 371382. doi: 10.1016/j.oneear.2020.08.009

Wurtzebach, Z., and Schultz, C. (2016). Measuring ecological integrity: history, practical applications, and research opportunities. BioScience 66, 446-457. doi: 10.1093/biosci/biw037
Conflict of Interest: The authors declare that the research was conducted in the absence of any commercial or financial relationships that could be construed as a potential conflict of interest.

Publisher's Note: All claims expressed in this article are solely those of the authors and do not necessarily represent those of their affiliated organizations, or those of the publisher, the editors and the reviewers. Any product that may be evaluated in this article, or claim that may be made by its manufacturer, is not guaranteed or endorsed by the publisher.

Copyright $(2022$ Grantham, Evans, Lieberman, Robinson, Elsen, Ferrier, Kearney, Maurer, Surya, Spindler, Stasak, Trezise and Watson. This is an open-access article distributed under the terms of the Creative Commons Attribution License (CC BY). The use, distribution or reproduction in other forums is permitted, provided the original author(s) and the copyright owner(s) are credited and that the original publication in this journal is cited, in accordance with accepted academic practice. No use, distribution or reproduction is permitted which does not comply with these terms. 